\title{
Negotiation and Contracting in Collaborative Networks
}

\author{
Ana Inês Oliveira ${ }^{1}$ and Luis M. Camarinha-Matos ${ }^{1,2}$ \\ ${ }^{1}$ UNINOVA, Instituto de Desenvolvimento de Novas Tecnologias, Campus da Caparica, \\ Quinta da Torre, 2829-516 Monte Caparica, Portugal \\ ${ }^{2}$ Faculty of Sciences and Technology, New University of Lisbon, Campus da Caparica, Quinta \\ da Torre, 2829-516 Monte Caparica, Portugal \\ \{aio, cam\}@uninova.pt
}

\begin{abstract}
Due to the increasing market turbulence, companies, organizations and individuals need to tune their actuation forms so that they can prevail. It is particularly essential to create alliances and partnerships for collaborative problem solving when responding to new businesses or collaborative opportunities. In all types of alliances it is necessary to establish agreements that represent the rights and duties of all involved parts in a given collaboration opportunity. Therefore, it is important to deeply understand the structures and requirements of these alliances, i.e. what kind of members does the alliance have, what kind of protocols may be implied, how conflicts may possibly be resolved, etc. Moreover to these requirements, also the required support tools and mechanisms have to be identified. For that, this paper presents a research work that is being carried in the negotiation and contracting field, in order to promote agility in collaborative networks.
\end{abstract}

Keywords: Collaborative networks, negotiation, agreement, virtual organization creation, virtual organization breeding environment, agility, reliability.

\section{Introduction}

Due to the persistent market instability it is increasingly mandatory that companies and organizations increase their agility and promptly react and respond to business or collaboration opportunities that occur. Occasionally, they might not be able to react and respond by themselves, and consequently, have to collaborate with their peers. For that, the topic of collaborative networks $(\mathrm{CNs})$ appears significantly promising. If the enterprises or the organizations share a common interoperable infrastructure, common operating principles, common cooperation agreements, and a base of trust among them, then their ability to rapidly form a virtual organization (VO) is increased [9]. Nevertheless, to form a VO, besides the important mission of selecting the adequate partners with the most suitable competencies to respond to the collaboration opportunity $(\mathrm{CO})$ characteristics, it is also of extreme importance to have a robust and reliable negotiation mechanism that enables the possible VO partners to negotiate in order to achieve a consensus VO agreement during the VO creation process. This VO agreement will then be the basis for the governing principles of the VO during its operation phase.

L.M. Camarinha-Matos, P. Pereira, and L. Ribeiro (Eds.): DoCEIS 2010, IFIP AICT 314, pp. 8,-92, 2010. (C) IFIP International Federation for Information Processing 2010 
Furthermore, depending on the different domains or on the different objectives, CNs, and specifically, VOs may appear in a variety of forms with a variety of behavioral patterns [8]. Thus, it is also important to have into account that each environment must be treated accordingly to its context and to its fundamental characteristics. This also applies to the negotiation process that will also have to be adaptable to each specific case. Therefore, although significant work has already been carried out in the area of $C N s$ and in the area of electronic contracting, one gap still exists that leaves space for additional research work, that is:

How can different collaborative environments be characterized in terms of their negotiation space, and how can the electronic negotiation process for consortia creation be handled to increase agility and reliability?

\section{Contribution to Technological Innovation}

Whenever a business or collaboration opportunity appears, if the interested entities are clustered into VO Breeding Environments (VBEs), the chance of acquiring the business opportunity is higher. Nevertheless, although the mechanisms and models provided by the VBE to its members already facilitate the VO formation, one important stage that is specific for each case is the negotiation between possible $\mathrm{VO}$ partners due to the numerous differences that those partners might have, for example, cultural differences. Thus, having into account this background, the motivation of this work is on the negotiation process that happens during the VO creation phase, which certainly has a relevant impact on the agility and reliability of the process, and can ensure the proper functioning of the VO during its operation phase. From this negotiation process the main outcome will be the VO consortium agreement that will represent the governing rules and principles of the consortium during its operation phase and it can include negotiation of rights and duties of all partners involved, but also can include for example, some sections on intellectual property rights, partners' benefits and shared risks.

For this significant topic on collaborative networks, proper technological support must be provided. For that, this work contributes with an identification and preliminary characterization of technological tools that can be related to the topic and for the consolidation of important characteristics of the negotiation process in the formation of collaborative consortia.

\section{Related Work}

As mentioned in the previous sections, the most important fields of this work are: the collaborative networks, in particular virtual organization creation and its related environment; and the negotiation and contracting. Therefore, in the next two subsections a brief outline and discussion on these areas is described.

Virtual Organization Creation and its Related Environment. The Virtual Organization (VO) paradigm constitutes one of the first manifestations of the collaborative networks. Being the concept developed and applied in several domains and areas, many contributions for the characterization and modeling of the paradigm 
can be found in the literature, as exemplified by [7] and [9]. The main idea behind this concept is basically of a temporary consortium of enterprises and/or organizations, geographically dispersed, that strategically join their competencies to rapidly respond to a business or collaboration opportunity. Typically VOs are supported by computer networks [4] [5]. Nevertheless, to enable the rapidness in the VO creation process, it is necessary that enough information is available about potential partners and that they are ready and prepared to participate in such collaboration. This readiness includes the existence of common models and infrastructures that can be achieved if the VO creation happens in the context of a VO Breeding Environment (VBE). Contrary to the VO that is a temporary collaboration, the VBE is a long-term alliance of the member organizations that provides the necessary means for the VO creation [3] [9]. Therefore, the $\mathrm{VO}$ creation process, that is triggered by a CO during the operation phase of a VBE, is well identified and characterized, including its structure, requirements, working flow, actors involved, and technological tools that can be used for each phase [10].

For most of the phases of the VO creation, a negotiation process might be required, for example to settle on agreements among possible VO partners. In this context, negotiation and agreement establishment appears as a major issue for VO, namely during its creation phase, but also potentially in its evolution phase, for example if during the VO operation phase a VO partner might need to be added or replaced [6] or to resolve some conflicts among network participants, that are inevitable [14].

Negotiation and Contracting. Negotiation is an interactive communication and decision-making process between two or more parties who seek a consensus decision and cannot apply unilateral actions to achieve their objectives [19].

As negotiation processes involve a transversal, multi- and inter-disciplinary approach, it is necessary to have a holistic view of the problem, making use of multiple methodologies and paying attention to the practical details [12]. So, a negotiation process can rely on several mechanisms such as: auctions, game theory, intelligent agent mechanisms, etc. [17]. Nevertheless, such process if often conducted by human actors that in the last instance are the ones responsible for decision-making. Although some works try to insert some automation into the negotiation process [13], this continues to be a rather difficult issue. The main obstacle is to produce a context-independent solution [2], and thus only partial and very specific solutions and prototypes with practical relevance are available, as is for example the case of the eLegal project [20] where the main goal was to develop solutions to legal issues related to VOs in the area of the civil construction. Nevertheless this framework would be prepared specifically for each project. Furthermore, the legal and contractual issues associated to each contract/agreement concentrated on the ICT perspective can be found in [21].

Focusing on the contract or agreement being established among the partners that will form a VO, that is, the internal consortium agreement, its relevance is to establish the necessary clauses to regulate the consortium behaviour during the VO operation phase. In this way, special attention should be put into e-contracting forms as they can capture and describe the rights and duties of all VO partners [18], as well as specification of penalties to apply to those that do not satisfy the agreement.

Computer assisted negotiation and e-contracting is expected to provide a faster and cheaper solution than traditional contracting for geographically distributed consortia 
formation. Several significant characteristics of the e-contracting process can be found in [1]. Moreover, an electronic contract can have both a machine readable and human readable representation, that is usually required when the contract creation and management involves the participation of human beings.

Moreover, the advances in the negotiation domain stem from the use of information systems and communication media to support negotiation processes and decisions. Negotiation Support Systems (NSS) are interactive, computer-based tools intended to support negotiating parties in reaching agreements. These systems provide varying levels of structured communications and decision support; and offer both dispute resolution mechanisms (i.e. dealing with infringements of existing contracts) as well as contract formation services (i.e., creating new agreements) [19].

Progress in this area during the last years has highlighted a number of important topics that need to be considered when developing processes and methodologies for negotiation and e-contracting, including Contract Models, Ontology, Contract Framework, Electronic Institutions, and Digital Signature.

Procedures for e-contracting and negotiation are also important in relation to the ISO 9000 certification as they can ensure clearly defined and repeatable procedures within the $\mathrm{CN}$ as a whole and not only within the companies that are members of a collaborative network [16].

However, further research in this area is mandatory due to the evolution on technology and new requirements that are constantly challenging the current processes. Some of these challenges are related to communication channels, use of artificial intelligence methods, intellectual property rights, electronic institutions, etc.

\section{Research Contribution and Innovation}

The rapid formation of VOs to respond to a business opportunity is crucial in order to enable organizations and companies to survive in turbulent market conditions. Nevertheless various empirical studies still show a very high percentage of failures in collaborative consortia. If they succeed it is then an indicator of agility and reliability that are two factors that are increasingly more important. It is thus in the VO creation process that additional effort has to be done if organizations / companies want to be successful. For that, among other factors the consortium negotiation process among partners is essential since it is where partners reach agreements and commitments to regulate the future collaboration.

When a VO is created in the context of a VO Breeding Environment (VBE), most of these aspects are agreed at the VBE level prior to any consortia formation. On the VOs perspective, negotiation mechanisms might be applied in different stages, namely: (i) during VO creation either for negotiating with the potential customer, or to negotiate an internal VO agreement; or (ii) for VO agreement amendment, meaning that it can be used for partners' inclusion or replacement, and changes of roles. The establishment of internal agreements is one of the foremost negotiation needs as they will determine the behavior of the networks, and thus represents an issue of special relevance during the VO creation process [11]. Table 1 summarizes the main phases of VO creation, highlighting the ones that require some negotiation level when a $\mathrm{CO}$ is already guaranteed. The case when there has to be a quotation process can be found in [11]. 
Table 1. VO creation phases

\begin{tabular}{l|l|l}
\hline \multicolumn{2}{c|}{ VO creation phase } & \multicolumn{1}{c}{ Main focuses } \\
\hline $\begin{array}{l}\text { Preparatory } \\
\text { planning }\end{array}$ & $\begin{array}{l}\text { CO identification and } \\
\text { characterization }\end{array}$ & $\begin{array}{l}\text { Who? Where and how? Which patterns of } \\
\text { collaboration? How to structure the VO? Any } \\
\text { initial template model? }\end{array}$ \\
Rough VO planning & $\begin{array}{l}\text { Who? Where? Which criteria? Which base } \\
\text { information? Profiles? Decision support? }\end{array}$ \\
VO launching & $\begin{array}{l}\text { Detailed VO planning } \\
\text { Contracting } \\
\text { VO setting up }\end{array}$ & $\begin{array}{l}\text { Who? Negotiation process? Contracts, rules } \\
\text { templates? Agreements? } \\
\text { Common infrastructure? Governing } \\
\text { principles? Detailed plans? }\end{array}$ \\
\hline
\end{tabular}

Due to the geographical distribution of potential participants in a VO, various attempts have been made to use some form of electronic support to the negotiation processes. Nevertheless past experiences demonstrate that the willingness of some parties to participate in online negotiations is difficult to achieve [19]. As a first step, it is important to ensure to all involved negotiating parties that by the introduction of electronic negotiation mechanisms no full automation is aimed but rather some computerized assistance. Furthermore, when the electronic negotiation fails, meeting face-to-face will still have to be considered as an option. So, in an electronic negotiation context, performance improvement includes enhancement of efficiency and effectiveness of both the process and the outcome, together with the flexibility of human intervention in decisions. Moreover, with the rapid growth of web-based services and global trade, there is also some commercial potential for web-based Negotiation Support Services (WNSS), as already supported by [19].

Negotiation Services. Becoming clear that the negotiation plays an important role in the process of the formation of collaborative consortia, it is important to create an environment that is the more explicit and traceable as possible.

To build a system capable of performing such negotiation during VO creation, the current work proposes some areas that need to be considered, namely the interaction with other systems and the negotiation support modules. In terms of interaction with other systems, a robust negotiation process will have to directly interact with the VBE information system to have access mainly to the VBE members profile and competencies as well as collaboration history. Regarding negotiation support modules, the ones identified (so far, more will appear during the accomplishment of this research work) are the following:

- Agreement editor that will enable: agreement templates generation; agreements templates instantiation; agreement configuration to current situation/context;

- Virtual negotiation room (VNR) that is a virtual space (online) where each participant will be able to negotiate and/or discuss certain issues/clauses of the agreement; and

- Support for notary services to guarantee on one hand the authenticity and validity of the agreements, and on the other hand to provide a safe deposit for documentation. The functionality to support auditing and supervision is also foreseen. 
Fig. 1 illustrates the negotiation modules represented by the described application services together with a characterization of a $\mathrm{CO}$ and a partner's search engine. Also data bases services have to be considered in the process. Moreover, Fig1. also represents the main interactions with the VBE information system and with the relevant actors involved (the VBE members that will be the potential VO partners and the VO planner). All of the users can have access to negotiation services with correct authentication means through their web browsers.

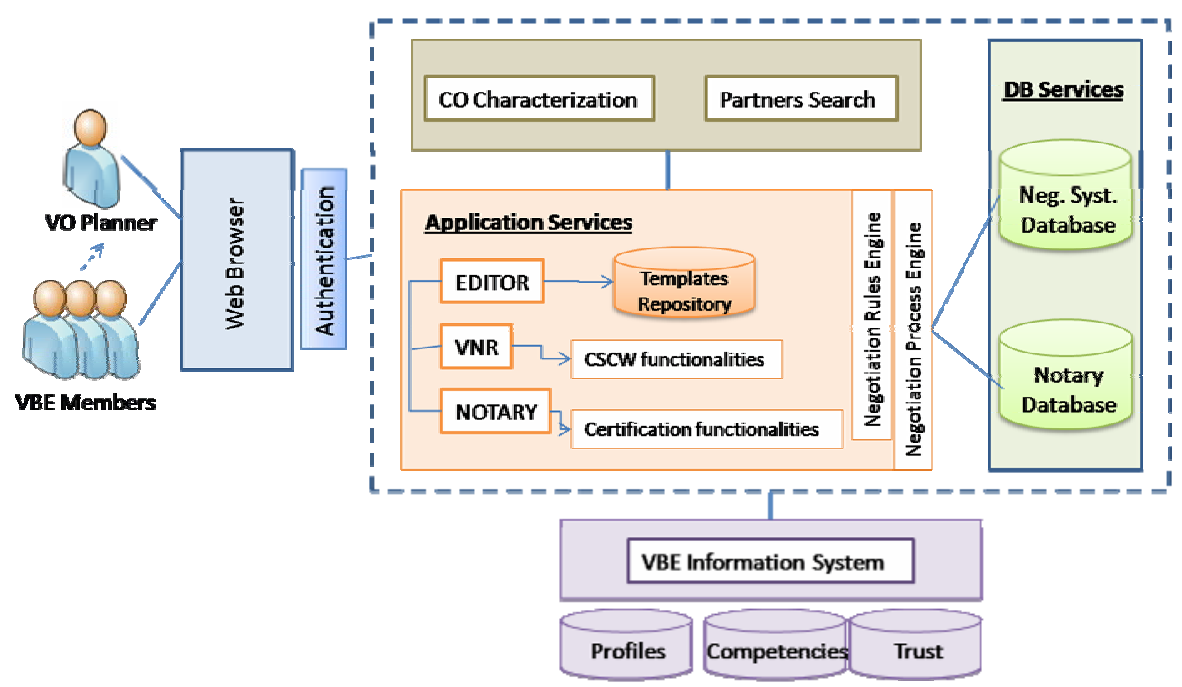

Fig. 1. Negotiation modules and interactions

Negotiation Model. With regards to the identified modules and interactions, it is necessary to reflect on new models of negotiation agreements since many different environments and participants might be considered. For that it is important to characterize those differences and model them. By doing this, it will be possible to instantiate the proper mechanisms for negotiation depending on different contexts. Thus, fundamental topics emerge, such as:

- Identifying network members whose agreement is necessary;

- Identifying the scope and (legal) jurisdiction of the network;

- Addressing issues of the network's legitimacy;

- Negotiating the ground rules;

- Discussing administration and allocation of responsibilities;

- Negotiating the decision rules for closure of an issue;

- Identifying a system for resolving impasses; and

- Identifying a decision process for ending the network.

In Fig. 2 it is then illustrated a negotiation process in VO creation that takes into account the previous topics. 


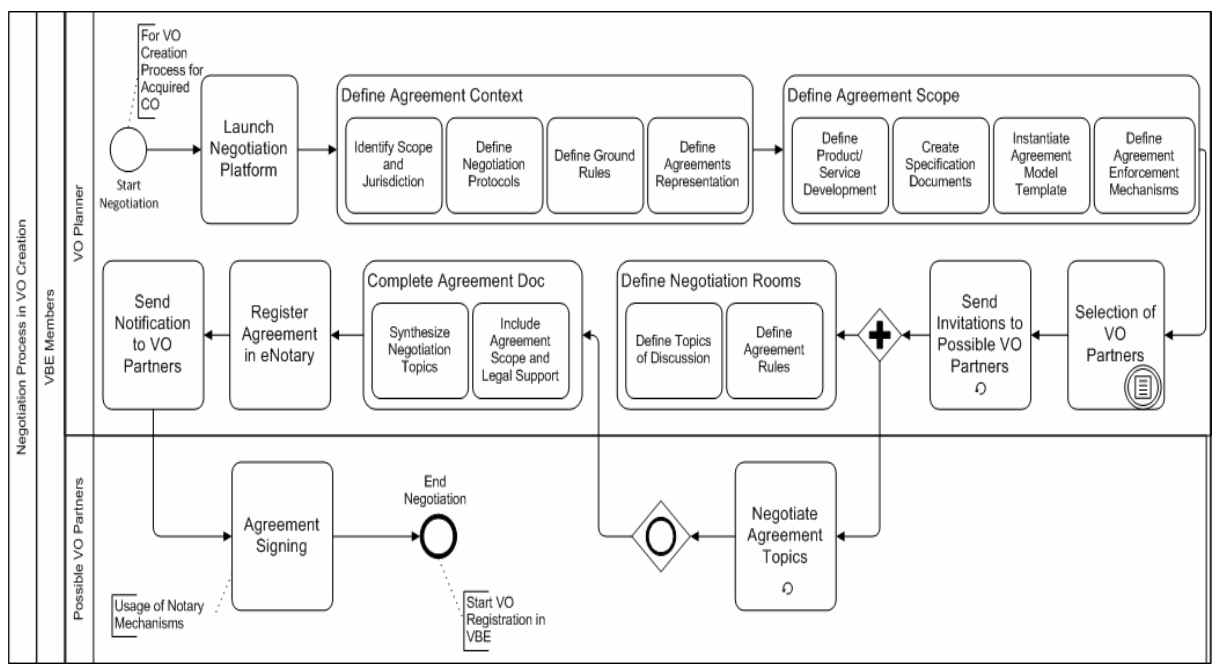

Fig. 2. Negotiation process in VO creation

Experiment Case: WizAN. To support some of the previous concepts, an Agreement Negotiation Wizard (WizAN) was developed [15]. The assumption is to use the tool for the $\mathrm{VO}$ creation process to assist in the agreement establishment in the $\mathrm{VBE}$ context. Also, the tool is aimed at assisting the human users in their decision making; therefore, it was designed with computer-assisted functionalities and not as a fully automated system. The main outcome of WizAN is then the internal consortium agreement summarizing the results of the negotiations / discussions that are performed during the VO creation process.

The full negotiation process is guided by an agreement template composed of a number of sections where each one refers to a specific topic to be negotiated. When a negotiation topic is created a virtual negotiation room (VNR) is "opened" in the system, and it is associated to a specific section of the agreement where a link to the topic is kept. Several VNRs might be created to negotiate all the topics that require discussion. Once all topics are agreed by the participants, the composite agreement can be assembled into a document that represents a compilation or integration of the agreements reached on all VNRs.

The actors involved in the process are therefore: VO planner who is responsible for the configuration and creation of the VO; and the VBE members that will act at this stage as potential VO partners. To assist the human actors in these processes, WizAN includes four main modules, namely: Contract Editor (CE), Virtual Negotiation Room (VNR), Support for Agreement Establishment (eNotary), and Assisted Contract Elaboration System (ACE). Table 2 illustrates the main functionalities of each of these modules.

Discussion of Results. Although this research is still in its initial stage, the preliminary study that led to the tool described in the illustrative case was developed in the scope of an European project, ECOLEAD, and positively evaluated in a real 
Table 2. WizAN's main functionalities [15]

\begin{tabular}{c|l}
\hline Functionality & \multicolumn{1}{|c}{ Description } \\
\hline Contract Editor (CE) & $\begin{array}{l}\text { Users can find the base information regarding the agreements being } \\
\text { established among the VO partners. Through CE the VO planner is } \\
\text { able to initiate, conduct, and monitor the VO creation; as it deals } \\
\text { with the general part of the agreement that is being established. } \\
\text { Is a virtual 'place' where the negotiation takes place. Through the } \\
\text { VNRs each participant can access the various negotiation topics and } \\
\text { discuss with the other involved participants in order to reach } \\
\text { agreements. For each negotiation topic one VNR is created. }\end{array}$ \\
Virtual Negotiation \\
Room (VNR) \\
$\begin{array}{l}\text { Is a module that allows clients to exchange information with a } \\
\text { warranty of authenticity and validity as well as providing them a } \\
\text { Agreement } \\
\text { Establishment } \\
\text { provides the functionality for partners to (digitally) sign agreements. } \\
\text { Collection of contract and negotiation object templates to support } \\
\text { the contracts creation. }\end{array}$ \\
Elabsisted Contract
\end{tabular}

scenario with a Swiss and a Chinese VBE supporting negotiations between partners from the two geographical areas [16]. As a result, it is possible to draw some positive conclusions, namely in terms of the focused negotiation process due to the usage of the VNRs and the possibility to use attached documents that also prevent misunderstandings, making the process more reliable. Moreover, a degree of authenticity is also guaranteed due to the existence of an eNotary service. Also, the system ensures the privacy of the information exchanged in the VNRs, guaranteeing that partners have access only to authorized information. Finally, by using such system, it is possible to reduce the negotiation time of the VO creation process, which increases the agility indicator.

Although the preliminary work has already developed some facilitates for the negotiation process in the VO creation, the process can still become more effective, but always depending on the availability of adequate information about the potential partners and their level of interestingness in the VO involvement. For instance, considering indicators of readiness of each partner to collaborate or their trustworthiness level can lead to a higher level of assistance during the negotiation process. Moreover, considering the three situations, already identified, in which negotiation can take place (during VO creation to negotiate with the potential customer, or to negotiate the internal VO agreement; and to do VO agreement amendments); it is necessary to investigate if it is possible to use the same negotiation methodology in all of them and how to evaluate the VO partners readiness and preparedness in each case. Depending on the results, a negotiation taxonomy can also be adjusted. Another research line of extreme importance is the eNotary service which is one of the key factors in this work mainly due to its safety and authenticity properties, and aim to extend its functionalities with support for auditing and supervision.

Another direction is to increase the level of intelligence of the negotiation wizard by analyzing some behavioral and emotional patterns (an aspect of affective computing) and reacting accordingly. On one hand, the patterns that may be analyzed are for example: delays in communication, language usage, etc., and on the other hand, the reactions that the system can have depending on the required automation 
level, could vary from alerts for human users of the system to automatic responses. In the last case (the more autonomous one), the multi-agent paradigm is one of the appropriated implementation directions.

\section{Conclusions and Further Work}

In collaborative environments, the process of consortium/team creation can become more agile and reliable if there is a framework that can rapidly create the appropriate conditions to electronically achieve a consortium agreement. This framework should consider the concepts already established in collaborative networks and create an environment that is customizable according to the different collaboration levels. The framework should also be able to let the involved participants clearly assume their duties, responsibilities and rights according to their defined roles.

Nevertheless, there are some areas where some research challenges remain. As an interesting topic for research is how to improve and better adapt the negotiation wizard to multidisciplinary and multicultural environments that are used by people and organizations with different business practices, languages, objectives and terminologies. Another promising direction is the application of machine learning and affective computing to take into account patterns of behavior and emotions of the involved parties. Thus, although several works already mention the negotiation phases and taxonomy, a research challenge is the definition and formalization of more specific negotiation protocols for collaborative networks. Negotiation with customer during the acquisition for a collaboration opportunity might also be considered in future. Nevertheless, through all of these conclusions, it is possible to assume that if the characteristics of a specific VBE are well defined, as well as its governance principles, the negotiation process can then be tuned accordingly and thus the agility in the $\mathrm{VO}$ creation process can increase.

Acknowledgments. This work has been supported by the Collaborative Networks and Distributed Industrial Systems Research Group of Uninova.

\section{References}

1. Angelov, S.: Foundations of B2B Electronic Contracting. PhD, Technische Universiteit Eindhoven, Eindhoven (2006) ISBN 90-386-0615-X

2. Angelov, S., Grefen, P.: An Approach to the Construction of Flexible B2B E-Contracting Processes. Technical Report TR-CTIT-02-40, Centre for Telematics and Information Technology, University of Twente, Enschede (2002) ISSN 1381-3625

3. Afsarmanesh, H., Camarinha-Matos, L.M.: A Framework for Management of Virtual Organization Breeding Environments. In: Camarinha-Matos, L.M., Afsarmanesh, H., Ortiz, A. (eds.) Collaborative Networks and their Breeding Environments, pp. 35-48. Springer, Heidelberg (2005)

4. Camarinha-Matos, L.M., Afsarmanesh, H.: Elements of a base VE infrastructure. J. Computers in Industry 5(2), 139-163 (2003)

5. Camarinha-Matos, L.M., Silveri, I., Afsarmanesh, H., Oliveira, A.I.: Towards a Framework for Creation of Dynamic Virtual Organizations. In: Camarinha-Matos, L.M. (ed.) Collaborative Networks and their Breeding Environments, pp. 69-80. Springer, Heidelberg (2005) 
6. Camarinha-Matos, L.M., Oliveira, A.I.: Contract Negotiation Wizard for VO Creation. In: Cunha, P.F., Maropoulos, P.G. (eds.) Digital Enterprise Technology, pp. 333-342. Springer, Heidelberg (2007)

7. Camarinha-Matos, L.M., Afsarmanesh, H.: Related work on reference modeling for collaborative networks. In: Camarinha-Matos, L.M., Afsarmanesh, H. (eds.) Collaborative Networks: Reference Modeling, pp. 15-28. Springer, Heidelberg (2008)

8. Camarinha-Matos, L.M., Afsarmanesh, H.: Collaboration Forms. In: Camarinha-Matos, L.M., Afsarmanesh, H. (eds.) Collaborative Networks: Reference Modeling, pp. 51-66. Springer, Heidelberg (2008)

9. Camarinha-Matos, L.M., Afsarmanesh, H., Ollus, M.: ECOLEAD and CNO Base Concepts. In: Camarinha-Matos, L.M., Afsarmanesh, H., Ollus, M. (eds.) Methods and Tools for Collaborative Networked Organizations, pp. 3-32. Springer, Heidelberg (2008)

10. Camarinha-Matos, L.M., Oliveira, A.I., Demsar, D., Sesana, M., Molina, A., Baldo, F., Jarimo, T.: VO Creation Assistance Services. In: Camarinha-Matos, L.M., Afsarmanesh, H., Ollus, M. (eds.) Methods and Tools for Collaborative Networked Organizations, pp. 155-190. Springer, Heidelberg (2008)

11. Camarinha-Matos, L.M., Oliveira, A.I., Sesana, M., Galeano, N., Demsar, D., Baldo, F., Jarimo, T.: A framework for computer-assisted creation of dynamic virtual organisations. International Journal of Production Research 47(17), 4661-4690 (2009)

12. Gimpel, H., Jennings, N.R., Kersten, G.E., Ockenfels, A., Weinhardt, C.: Negotiation, Auctions, and Market Engineering. In: International Seminar (Revised Selected Papers), Dagstuhl Castle, Germany, November 12-17. Springer, Heidelberg (2008)

13. Jennings, N.R., Norman, T.J., Faratin, P., O’Brien, P., Odgers, B.: Autonomous Agents for Business Process Management. Journal of Applied Artificial Intelligence 14, 145-189 (2000)

14. O'Leary, R., Bingham, L.B.: A Manager's Guide to Resolving Conflicts in Collaborative Networks, IBM Center for the Business of Government, Washington D.C (2007)

15. Oliveira, A.I., Camarinha-Matos, L.M.: Agreement Negotiation Wizard. In: CamarinhaMatos, L.M., Afsarmanesh, H. (eds.) Methods and Tools for Collaborative Networked Organizations, pp. 191-218. Springer, Heidelberg (2008)

16. Oliveira, A.I., Camarinha-Matos, L.M., Pouly, M.: Agreement Negotiation Support in VO Creation. In: Camarinha-Matos, L.M., Picard, W. (eds.), pp. 107-118. Springer, Heidelberg (2008)

17. Rocha, A.P., Oliveira, E.: An Electronic Market Architecture for the Formation of Virtual Enterprises. In: Proceedings of the IFIP TC5 WG5.3 / PRODNET Working Conference on Infrastructures for Virtual Enterprises: Networking Industrial Enterprises, October 27-28, pp. 421-432 (1999)

18. Rocha, A.P., Cardoso, H., Oliveira, E.: Contributions to an electronic institution supporting virtual enterprises' life cycle. In: Putnik, G.D., Cunha, M.M. (eds.) Virtual Enterprise Integration: Technological and Organizational Perspectives, pp. 229-246. Idea Group Publishing, London (2005)

19. Turel, O., Yuan, Y.: User Acceptance of Web-Based Negotiation Support Systems: The Role of Perceived Intention of the Negotiating Partner to Negotiate Online. Group Decision and Negotiation 16(5), 451-468 (2007)

20. Carter, C., Hassan, T., Mertz, M., White, E.: The eLegal project: specifying legal terms of contract in ICT environment. International Journal of Information Technology in Construction 6, 163-174 (2001)

21. Shelbourn, M., Hassan, T., Carter, C.: Legal and Contractual Framework for the VO. In: Camarinha-Matos, L.M., Afsarmanesh, H., Ollus, M. (eds.) Virtual Organization Systems and Practices, pp. 167-176. Springer, Heidelberg (2005) 